\title{
Effects of preweaning environmental enrichment on later problem-solving behavior in rats
}

\author{
A. IVINSKIS and JUDI HOMEWOOD \\ University of Newcastle, Newcastle, New South Wales, Australia
}

\begin{abstract}
Two experiments investigated the importance of visual sensory modality in mediating enriched environmental effects during the preweaning period, and the importance of onset and duration of the enriched experience during the same period. Rat mothers and pups were exposed together in an enriched environment for either 7 or 11 days at different periods from Day 1 to Day 21. Also included was a group of rats which received only handling from Day 11 to Day 21 postpartum and another group in which the mothers were exposed to the enriched environment during the last trimester of pregnancy. Some rats were tested at 27 days of age, and others were tested at 64 days of age in the Hebb-Williams maze test. It was found that exposure in the enriched environment for a period of 7 days before the eyes opened improved rats' problem-solving behavior above that of control rats and to the level of rats which received such experience after the eyes had opened. Handling of rats did not improve problem-solving behavior, nor did exposure during the gestation period. It was concluded that vision is not the most important factor in mediating effects during the preweaning period, since improvement in problem-solving behavior can occur before the visual system is fully developed. It was suggested that the beneficial enrichment effects might be mediated by the mother, who, in some way, transmits additional stimulation to the infant rat during this early stage of development.
\end{abstract}

Two lines of research have indicated that increased stimulation early in life can significantly modify later behavior. In one group of studies, handling or electric shock administered during the preweaning period have resulted in decreased emotionality and, generally, better adaptation by the organism to environmental demands in later life (Daly, 1973; Denenberg, 1964; Denenberg \& Haltmeyer, 1967; Levine, 1969). In the other group of studies, increased complexity of the environment has been shown to produce physiological and anatomical brain changes in rats (Rosenzweig, 1971; Walsh and Cummins, 1975) and to yield significant improvement in problem-solving behavior, (Forgays \& Forgays, 1952; Hymovitch, 1952; Ivinskis \& Ivinskis, 1976; Morgan, 1973; Nyman, 1967; Schweikart \& Collins, 1966; Smith, 1972).

There has been a general acceptance in the literature that early enriched experience must occur after weaning and before maturity in order to produce the most pronounced changes in problem-solving behavior (Denenberg, Woodcock, \& Rosenberg, 1968; Hymovitch, 1952). More specifically, the optimum postweaning period for enriched stimulation in rats has been suggested to be between 22 to 43 days (Forgays \& Reid, 1962) and between 50 to 60 days (Nyman, 1967). However, enriched experience before weaning (e.g., 0-21 days) can also significantly im-

Requests for reprints should be sent to Dr. A. Ivinskis, Department of Psychology, University of Newcastle, Newcastle, New South Wales 2308, Australia. prove later problem-solving behavior (PSB). Forgays and Reid (1962) report that rats exposed from 0 to 21 days to an enriched envrionment performed better than control rats, and they concluded that very brief exposure in a wider environment in early life can have rather lasting effects. Haywood and Tapp (1966) suggested that stimulation during the 15- to 20-day period could alter rodents' later capacity for problemsolving. Denenberg et al. (1968) found that enriched experience before weaning improved later PSB. They commented that "because of extreme immaturity of the rat at birth it is likely that enrichment during infancy only has effect upon the rat during the last week to 10 days of the preweaning period, i.e. after $S$ had developed proficiency in locomotion and after the eyes have been opened" (Denenberg et al., 1968, p. 535). Finally, Rosenzweig (1971) suggested that enriching the environment from Day 6 on produces measurable effects on brain anatomy without handling or stressing the pups. Rosenzweig concluded that brain organization is affected by experiential variables from the time the rat first begins to leave the nest and expose itself to the external environment.

Changes in behavior produced by environmental stimulation during the preweaning period have usually been explained in terms of direct alterations of the neuroendocrine mechanisms which behaviorally are manifest in lower levels of emotionality (Denenberg \& Zarrow, 1971). There are, of course, other ways of looking at this issue. Evidence has accumulated that 
the mother is an important agent in supplying stimulation and maintaining the arousal of the infant, and Walsh and Cummins (1975) have proposed that an internal arousal state mediates the effects of enrichment. It is known that the infant rat emits signals and also responds to its mother's cues very early in life (Allin \& Banks, 1972; Bell, Nitschke, Bell, \& Zachman, 1974; Leon, Galef, \& Behse, 1977; Noirot, 1972). Stimuli emanating from the pups induce the onset of maternal caretaking activities (e.g., retrieving, licking, etc.), and more spontaneous maternal behavior is evident towards the younger (1-8 days) than toward the older (9-16 days) rats (Stern \& MacKinnon, 1978). Presumably, older pups would be capable of maintaining sufficient levels of arousal by self-stimulation, since from about Day 14 the infant rat can effectively use its eyes and ears for distance perception. Furthermore, tactile and vestibular stimulation is functional in the rat during the later part of gestation, and auditory and visual sensitivity develops before the external auditory canals open and before the eyelids open (Gottlieb, 1971). This evidence suggests that there is much interaction between the mother and the pups during the preweaning period, and that some of the infants' sensory receptors are already functional shortly after birth. It is therefore possible that, through this mother-infant relationship, the beneficial effects of the enriched environment (which the mother also experiences) can be transmitted to the infant rat, particularly during the early part of the preweaning period.

This paper reports two experiments designed to examine the role of onset and duration of the enriched experience, and the importance of the visual sensory modality as the mediator of the enriched environmental effects during the preweaning period.

\section{EXPERIMENT 1}

The purpose of this experiment was to examine changes in PSB when female rats and their pups were exposed to an enriched environment from Day 11 to Day 21 postpartum and when other rats were handled during the same period. The period of exposure is shorter than that used by Denenberg et al. (1968) and Forgays and Reid (1962). However, it is during this period when the infant rats become more mobile and the auditory and visual systems develop more fully.

Handling during the preweaning period has been found to decrease emotionality in rats (Denenberg \& Zarrow, 1971), and it has been proposed that reduced emotionality could be an important contributing factor which might facilitate PSB. It should be pointed out, however, that Denenberg and Morton (1962) found that preweaning handling did not influence Hebb-Williams problem-solving behavior. Since, according to Daly (1973), the evidence on this point is not entirely clear, it was considered desirable to include a handled group in the present experiment.

\section{Method}

Subjects. Six pregnant female albino rats were obtained from the University of Newcastle animal colony and were randomly assigned to three groups, two females per group. The enriched group received enriched environmental experience from Day 11 to Day 21; the handled group received handling during the same period; and the control group was housed in standard maternity cages. When a litter was born, the number of pups was culled to eight in each case. The rats were housed in a room where the temperature was set at $21^{\circ} \pm 1^{\circ} \mathrm{C}$ and a 10:14-h L-D cycle was maintained. Food and water were provided ad lib. The final sample consisted of 30 rats, 5 rats being selected from each litter.

Apparatus. The enriched environment was identical to that de scribed by Ivinskis and Ivinskis (1976). Briefly, it consisted of a cage $(70 \times 54 \times 30 \mathrm{~cm})$ with metal walls, wire mesh lid, and wood shavings on the floor. It was equipped with a wire platform suspended above the floor, two ladders attached to the platform, metal cutouts-a triangle, a square, and a circle-suspended from the wire-mesh lid, a see saw, and a swing. The control group subjects were housed in standard maternity cages $(25 \times 38$ $\times 17 \mathrm{~cm}$ ) which contained only a water bottle and food.

Problem-solving ability was tested using the Hebb-Williams maze. The apparatus and the pretraining and testing procedure were as described by Rabinovitch and Rosvold (1951). Only 2 of the original 12 test problems suggested by Rabinovitch and Rosvold were used, Problem 5 and Problem 10. These two problems were chosen because they were in a number of earlier studies in this laboratory, and it was considered desirable to preserve standard testing conditions so that a direct comparison could be made between studies.

Procedure. When the pups were 11 days old, two females and their pups from the enriched group were transferred to separate enriched environments, while four other females and their pups remained in separate standard cages. The pups of two of these females were assigned to the handled group and were handled daily. Handling consisted of removing the mother from the cage and then picking up each individual pup and place it in a small container which had wood shavings on the floor. The pups were left in the containers for $3 \mathrm{~min}$ and then returned to the cage. This was done at the same time each day until the rats were 21 days old. The two mothers and their pups in the control group remained in their separate standard cages throughout Days 1-21 and were not handled.

All the pups were weaned at 22 days and were housed in standard laboratory cages. Pretraining for the Hebb-Williams maze started at 23 days of age, and testing on Problems 5 and 10 was carried out when the rats were 27 days old. The HebbWilliams test problems were presented in a counterbalanced order, and the experimenter who tested the subjects was not aware to which experimental conditions the rats belonged.

\section{Results and Discussion}

Problem-solving behavior was evaluated in terms of the error scores obtained on the two Hebb-Williams test items. Since there was no significant difference between the error scores on the two test items $(F>1)$, the scores were combined, and the means and standard deviations for each group are presented in Table 1. According to Abbey and Howard (1973), it cannot be assumed that subjects from the same litter are necessarily independent. Consequently, and analysis of variance was carried out on the error scores to determine whether a between-litter difference was present; no such difference was found $[F(3,24)=.61]$. A significant difference in error scores was found between the groups, however $[F(2,24)=6.82, p<.01]$. Scheffé tests indicated that the enriched group differed significantly from the other two groups, but there 
Table 1

Means and Standard Deviations of Errors in Hebb-Williams Maze on Test Problems 5 and 10 Combined

\begin{tabular}{ccc}
\hline \multirow{2}{*}{$\begin{array}{c}\text { Rearing } \\
\text { Condition }\end{array}$} & \multicolumn{2}{c}{ Hebb-Williams Scores } \\
\cline { 2 - 3 } & Mean & SD \\
\hline Enriched & 44.6 & 17.2 \\
Handled & 67.0 & 12.3 \\
Control & 63.9 & 15.1 \\
\hline
\end{tabular}

was no significant difference between the handled and the control groups.

These results show that rats exposed to an enriched environment for 11 days during the preweaning period significantly improve in their PSB when compared with handled and control rats. These findings generally agree with previous observations (Denenberg et al; 1968; Forgays \& Reid, 1962), but indicate that a period of exposure considerably shorter than that used previously can have beneficial effect on PSB in rats. The results also show that additional handling during the preweaning period (which is expected to decrease emotionality) did not have any significant effect on PSB, and this is in agreement with the findings reported by Denenberg and Morton (1962). In fact, rats that were handled in this experiment performed at the same level on Hebb-Williams problems as did control animals.

\section{EXPERIMENT 2}

This experiment examined the role of visual pattern stimulation in producing the improvement in PSB found in Experiment 1. If visual pattern stimulation played a vital part in the improvement of PSB, rats exposed to the enriched environment for only a few days before weaning (when their eyes were open) should perform better on the Hebb-Williams tests than rats experiencing the same enriched environment during the last week of gestation or during the postnatal period when the eyes were still closed. It was considered desirable in this experiment to test PSB at a later age than was done in Experiment 1 to insure that the obtained differences were of an enduring nature.

\section{Method}

Subjects and Apparatus. Eight pregnant females were obtained from the University of Newcastle animal colony. The selection of subjects was the same as described in Experiment 1. The final sample consisted of 32 rats.

The housing, the enriched environments, and the Hebb-Williams tests were the same as those used in Experiment 1.

Procedure. There were three experimental groups and one control group. In the enriched-1 group (E1), two pregnant female rats were placed in separate enriched environments from the beginning of the last trimester of pregnancy until the birth of the litter. When the pups were born, the mothers and the pups were returned to separate standard maternity cages. In the enriched-2 group (E2), two mothers and their pups were transferred into two separate enriched environments from birth to 7 days postpartum. In the enriched-3 group (E3), two mothers and their litters were placed in two separate enriched environments for 7 days shortly after the pups' eyes opened (i.e., from Day 15 to Day 21). Thus, each of these groups received an equal amount of exposure to the enriched environments, but at different developmental stages. The control group female rats and their pups were housed in standard maternity cages from birth until weaning. At 22 days of age, all animals were weaned and transferred to standard laboratory cages.

Testing for PSB in the Hebb-Williams maze was carried out when the rats were 64 days of age. Problem 5 and Problem 10 were presented in a counterbalanced order, and training and testing procedures were the same as in Experiment 1.

\section{Results and Discussion}

The total number of errors made by each subject on the two Hebb-Williams test problems provided the raw scores for analysis. An analysis of Hebb-Williams errors to determine whether between-litter differences existed (Abbey \& Howard, 1973) yielded no such differences $[F(4,24)=1.02]$. The main effect of test problems (Problems 5 and 10) was also found to be not significant, and therefore both problems could be regarded as being of equal difficulty and so were combined for further analysis. The obtained means and standard deviations of the combined Hebb-Williams error scores are presented in Table 2 .

Three planned orthogonal comparisons were then made on the data in Table 2. First, to determine if environmental enrichment, as such, had a significant effect on PSB, the mean error score of the control group was compared with the combined mean scores for the three enriched groups (E1, E2, and E3). A significant effect was found $[F(1,28)=23.93, p<.01]$, indicating that early exposure to the enriched environment significantly improved PSB when compared with the control group's performance. Second, to determine if a significant change occurred in PSB between subjects experiencing the enriched environment in the prenatal and the postnatal stages of development, the mean error score of Group E1 was compared with the combined mean error scores for Group E2 and E3. It was found that postnatal enriched experience significantly improved PSB when compared with prenatal enrichment $[F(1,28)=4.38, p<.05]$. Finally, there was no significant difference in PSB between Group E2 (before eyes open) and Group E3 (after eyes open).

The obtained results indicate that beneficial enriched environment effects (as measured by PSB) can be produced before pattern vision becomes possible in rats. The results indicate further that early environ-

Table 2

Means and Standard Deviations of Errors in Hebb-Williams Maze on Test Problems 5 and 10 Combined of Rats Exposed to Enriched Environment at Different Developmental Stages

\begin{tabular}{llrr}
\hline Groups & \multicolumn{1}{c}{ Enriched Experience } & Mean & SD \\
\hline E1 & Last 7 days gestation to birth & 55.6 & 10.5 \\
E2 & Birth to 7 days postpartum & 46.4 & 10.3 \\
E3 & From Day 15 to Day 21 postpartum & 48.5 & 8.7 \\
Control & No enriched experience & 70.8 & 8.2 \\
\hline
\end{tabular}


mental experiences appear to exert relatively durable influences on PSB. This fact is evidenced by the E2 rats' performance on Hebb-Williams tests conducted 57 days following the enriched environmental treatment. Exposure of the pregnant female rat during the last stage of gestation in the enriched environment had no significant effect on PSB when offspring were tested 64 days later. Thus, the "benefits" which the mother might have derived during such an exposure were not transmitted to the fetus. It seems that for significant improvement to occur in offspring, behavior environmental stimulation must be provided during the postnatal period.

\section{GENERAL DISCUSSION}

The major finding in the two studies reported here is that exposure of the infant rat, together with the mother, in an enriched environment during the preweaning period can significantly improve later PSB. It appears to make relatively little difference whether the rats receive enriched stimulation during the period of Days 0 to 7, Days 15 to 21, or Days 11 to 21, or whether they receive such stimulation for a period of 7 or 11 days. The observed changes in PSB (as measured by Hebb-Williams maze errors) appear to be quite similar. This suggests that during the preweaning period a relatively short-duration treatment, given at almost any preweaning stage, is sufficient to produce significant behavioral effects. Accordingly, it appears that the infant rat can benefit from enriched environmental exposure before the sensory systems are fully developed and well before the infant is capable of efficient locomotion, before it can leave the nest and explore the surrounding environment. From this it can be concluded that more complex visual stimulation (which becomes possible after the rat opens its eyes) is not the only effective, or apparently the most important, route (as suggested by Denenberg et al; 1968) that mediates such early enrichment effects.

The obtained results further indicate that the improvement in PSB is evident not only when testing is done shortly after the environmental treatment but also after a period of 21 and 57 days, and this reflects the enduring nature of the changes in PSB. It is worth noting, in this context, that Forgays and Reid (1962) obtained preweaning enrichment effects when the rats were tested after 100 days and that Denenberg et al. (1968) obtained similar results after 350 days.

It remains to be established now how the effects are produced and what systems are modified in the infant organism as a result of the early experience. One possible explanation is that, during the early stages of development, the mother plays an important part in the mediation of the enriched experience, since the immature sensory systems of the infant would prevent the organism from benefiting from such stimuli directly. It is, thus, feasible that when the mother (together with the pups) is exposed in a more complex, enriched environment, the mother spends more time outside the nest exploring the surroundings, and upon return to the nest spends more time "handling" the pups ("fussing" around them). It is possible that, in this way, the mother provides additional stimulation by increasing the infants' internal arousal level. According to Walsh and Cummins (1975), the animals' arousal state mediates the effects of enrichment during the postweaning period, and it is reasonable to suggest that it might also be implicated during the preweaning period. Since it has been shown that additional handling given to the handled group in Experiment 1 had no significant effect on the Hebb-Williams maze performance, it is possible that "handling" supplied by the mother is qualitatively, and perhaps even quantitatively, different from additional handling provided by an experimenter. Such an explanation, although not based on direct empirical evidence, is consistent with the propositions made by Russell (1971) and is also in agreement with the general findings reported by Allin and Banks (1972), Stern and Mackinnon (1978) and Villescas, Bell, Wright, and Knufner (1977).

The important contribution of the two experiments reported here is to point out that infants' behavior can be altered by what appears to be relatively minimal environmental treatment before the visual and the auditory sensory systems are fully developed. This is of considerable practical and theoretical significance, for if it can be established how the effects are produced it would provide insight into how the immature organism acquires environmental information and perhaps also reveal where the organism stores such information very early in life.

\section{REFERENCES}

Aвbey, H., \& Howard, E. Statistical procedures in developmental studies on species with multiple offspring. Developmental Psychobiology, 1973, 6, 329-335.

Allin, J., \& Banks, E. Functional aspects of ultra sound production in infant albino rats. Animal Behaviour, 1972, 20, 173-175

Bell, R., Nitschke, W., Bell, N., \& Zachman, T. Early experience, ultrasound vocalizations and maternal responsiveness in rats. Developmental Psychobiology, 1974, 7, 235-242.

DALY, M. Early stimulation of rodents: A critical review of present interpretations. British Journal of Psychology, 1973, 64, $435-460$

DenenBerg, V. H. Critical periods, stimulus input, and emotional reactivity: A theory of infantile stimulation. Psychological Review, 1964, 71, 335-351.

Denenberg, V. H., \& Haltmeyer, G. C. Test of the monotonicity hypothesis concerning infantile stimulation and emotional reactivity. Journal of Comparative and Physiological Psychology, 1967, 63, 394-396.

DenenberG, V. H., \& Morton, J. R. C. Effects of preweaning and postweaning manipulations upon problem-solving behavior. Journal of Comparative and Physiological Psychology, 1962, 55, 1096-1098

DenenberG, V. H., \& Zarrow, M. X. Effects of handling in infancy upon adult behavior and adrenocortical activity: Suggestions for a neuroendocrine mechanism. In D. H. Walcher 
\& D. L. Peters (Eds.), Early childhood: The development of regulatory mechanisms. New York: Academic Press, 1971.

Denenberg, V. H., Woodcock, J. M., \& Rosenberg, K. M. Long-term effects of preweaning and postweaning free-environment experience on rats' problem-solving behavior. Journal of Comparative and Physiological Psychology, 1968, 66, 533-535.

Forgays, G., \& Forgays, J. The nature of the effect of free environmental experience in the rat. Journal of Comparative and Physiological Psychology, 1952, 45, 322-328.

Forgays, D. G., \& Reid, J. M. Crucial periods for freeenvironmental experience in the rat. Journal of Comparative and Physiological Psychology, 1962, 55, 816-818.

GotTlieb, G. Ontogenesis of sensory function in birds and mammals. In E. Tobach, L. R. Aronson, \& E. Shaw (Eds.), The biopsychology of development. New York: Academic Press, 1971.

HAYwooD, H., \& TAPP, J. Experience and adaptive behavior. In N. Ellis (Ed.), International review of research into mental retardation. New York: Academic Press, 1966.

Нумоviтch, B. The effects of experimental variations on problem solving in the rat. Journal of Comparative and Physiological Psychology, 1952, 45, 313.321.

Ivinskis, A., \& Ivinskis, V. Effects of environmental change on problem-solving ability in rats. Psychological Reports, 1976, 38, 19-22.

Leon, M., Galef, B. G., \& Behse, J. H. Establishment of pheromonal and diet choice in young rats by odor preexposure. Physiology \& Behavior, 1977, 18, 387-391.

LEVINE, S. An endocrine theory of infantile stimulation. In A. Ambrose (Ed.), Stimulation in early infancy. London: Academic Press, 1969.

Morgan, M. J. Effects of post-weaning environment on learning in the rat. Animal Behaviour, 1973, 21, 429-442.

Noirot, E. Ultrasounds and maternal behavior in small rodents. Developmental Psychobiology, 1972, 5, 371-387.
Nyman, A. Problem solving in rats as a function of experience at different ages. Journal of Genetic Psychology, 1967, 110 , 31-39.

Rabinovitch, M. S., \& Rosvold, H. E. A closed-field intelligence test for rats. Canadian Journal of Psychology, 1951, 5, 122-128.

Rosenzwe IG, M. R. Role of experience in development of neurophysiological regulatory mechanisms and in organization of the brain. In D. N. Walcher \& D. L. Peters (Eds.), Early childhood: The development of self-regulatory mechanisms. New York: Academic Press, 1971.

Russeld, P. "Infantile stimulation" in rodents: A consideration of possible mechanisms. Psychological Bulletin, 1971, 75, 192-202.

Schweikart, G. I., \& Collins, G. The effects of differential postweaning environments on later behavior in the rat. Journal of Genetic Psychology, 1966, 109, 255-263.

Stern, J. M., \& Mackinnon, D. A. Sensory regulation of maternal behavior in rats: Effects of pup age. Developmental Psychobiology, 1978, 11, 579-586.

Sмiтн, H. V. Effects of environmental enrichment on open field activity and Hebb-Williams problem solving in rats. Journal of Comparative and Physiological Psychology, 1972, 80, 163-168.

Villescas, R., Bell, R., Wright, L., \& Knufner, N. Effect of handling on maternal behavior following the return of the pups to the nest. Developmental Psychobiology, 1977, 10, 323-329.

Walsh, R, N., \& Cummins, R. A. Mechanisms mediating the production of environmentally induced brain changes. Psychological Bulletin, 1975, 82, 986-1000.

(Received for publication May 1, 1979; revision accepted November $21,1979$. 